\title{
BMJ Open Impact of anaemia on lung function and exercise capacity in patients with stable severe chronic obstructive pulmonary disease
}

\author{
Jian Guo, ${ }^{1}$ Cong Zheng, ${ }^{2}$ Qiang Xiao, ${ }^{1}$ Sugang Gong, ${ }^{3}$ Qinhua Zhao, ${ }^{3}$ Lan Wang, ${ }^{3}$
} Jing $\mathrm{He},{ }^{3}$ Wenlan Yang, ${ }^{1}$ Xue Shi, ${ }^{1}$ Xingguo Sun, ${ }^{4}$ Jinming Liu ${ }^{1,3}$

To cite: Guo J, Zheng C Xiao $Q$, et al. Impact of anaemia on lung function and exercise capacity in patients with stable severe chronic obstructive pulmonary disease. BMJ Open 2015;5:e008295. doi:10.1136/bmjopen-2015008295

- Prepublication history for this paper is available online. To view these files please visit the journal online (http://dx.doi.org/10.1136/ bmjopen-2015-008295).

JG, $C Z$ and $Q X$ contributed equally.

Received 26 March 2015 Revised 19 August 2015 Accepted 21 August 2015

CrossMark

For numbered affiliations see end of article.

Correspondence to Professor Jinming Liu; jinmingliu2013@126.com

\section{ABSTRACT}

Objective: This study intended to search for potential correlations between anaemia in patients with severe chronic obstructive pulmonary disease (COPD; GOLD stage III) and pulmonary function at rest, exercise capacity as well as ventilatory efficiency, using pulmonary function test (PFT) and cardiopulmonary exercise testing (CPET).

Setting: The study was undertaken at Shanghai Pulmonary Hospital, a tertiary-level centre affiliated to Tongji University. It caters to a large population base within Shanghai and referrals from centres in other cities as well.

Participants: 157 Chinese patients with stable severe COPD were divided into 2 groups: the anaemia group (haemoglobin $(\mathrm{Hb})<12.0 \mathrm{~g} / \mathrm{dL}$ for males, and $<11 \mathrm{~g} / \mathrm{dL}$ for females $(n=48))$ and the non-anaemia group $(n=109)$.

\section{Primary and secondary outcome measures:} Arterial blood gas, PFT and CPET were tested in all patients.

Results: (1) Diffusing capacity for carbon monoxide (DLCO) corrected by $\mathrm{Hb}$ was significantly lower in the anaemia group $((15.3 \pm 1.9) \mathrm{mL} / \mathrm{min} / \mathrm{mm} \mathrm{Hg})$ than in the non-anaemia group $((17.1 \pm 2.1) \mathrm{mL} / \mathrm{min} / \mathrm{mm} \mathrm{Hg})$ $(p<0.05)$. A significant difference did not exist in the level of forced expiratory volume in $1 \mathrm{~s}\left(\mathrm{FEV}_{1}\right), \mathrm{FEV}_{1} \%$ pred, $\mathrm{FEV}_{1} /$ forced vital capacity (FVC), inspiratory capacity (IC), residual volume (RV), total lung capacity (TLC) and RV/TLC ( $p>0.05)$. (2) Peak Load, Peak oxygen uptake $\left(\mathrm{V}_{2}\right)$, Peak $\dot{\mathrm{V}}_{2} \%$ pred, Peak $\dot{\mathrm{V}}_{2} / \mathrm{kg}$, Peak $\mathrm{O}_{2}$ pulse and the ratio of $\mathrm{V}_{2}$ increase to WR increase $\left(\Delta \dot{\mathrm{V}} \mathrm{O}_{2} / \Delta \mathrm{WR}\right)$ were significantly lower in the anaemia group $(p<0.05)$; however, Peak minute ventilation (VE), Lowest $\dot{V} \mathrm{E} /$ carbon dioxide output $\left(\dot{\mathrm{V} C \mathrm{O}_{2}}\right)$ and Peak dead space/tidal volume ratio (VD/

VT) were similar between the 2 groups ( $p>0.05$ ).

(3) A strong positive correlation was found between $\mathrm{Hb}$ concentration and Peak $\mathrm{VO}_{2}$ in patients with anaemia $(r=0.702, p<0.01)$.

Conclusions: Anaemia has a negative impact on gas exchange and exercise tolerance during exercise in patients with severe COPD. The decrease in amplitude of $\mathrm{Hb}$ levels is related to the quantity of oxygen uptake.

\section{Strengths and limitations of this study}

- The results strongly indicate that oxygen carrying capacity may depend upon the level of haemoglobin for anaemic patients and oxygen delivery is crucial for the maintenance of oxidative metabolism.

- Anaemia had a negative impact on gas exchange and impaired exercise tolerance in severe chronic obstructive pulmonary disease (COPD) patients.

- A limitation of this study is that the proportion of female patients was small.

- The present data were derived from patients with severe (GOLD stage III) COPD and thus cannot be applied to the overall population of COPD patients.

\section{INTRODUCTION}

Chronic obstructive pulmonary disease (COPD) affects various functional and structural domains of the lungs and is recognised as a systemic disease that is frequently present in addition to other diseases. ${ }^{1}$ Polycythaemia, traditionally thought to be highly prevalent in COPD, is less frequent nowadays with a more rigorous correction of hypoxaemia. $^{2}$ Reversely, recent research shows that anaemia is highly prevalent in patients with COPD. ${ }^{3} 4$

Anaemia, which is a well-recognised comorbidity in many chronic illnesses, occurs in $10-30 \%$ of patients with COPD..$^{3-12}$ Anaemia has been related to increased mortality and morbidity including increased healthcare costs and hospitalisation..$^{3-12}$ Although cardiopulmonary exercise testing (CPET) parameters have been widely used to grade the severity of exercise limitation and provide a quantitative assessment on patients' ventilator response and cardiovascular response during exercise, ${ }^{13}$ all of which might be impaired due to anaemia. It has seldom been used for functional assessment 
of patients with COPD with anaemia. The present study is the first to investigate the impact of anaemia in patients with COPD using CPET in a Chinese population. The aims of our study were to (1) investigate the prevalence of anaemia in patients with stable severe COPD and (2) evaluate the impact of anaemia on pulmonary function at rest, ventilatory efficiency and exercise capacity in patients with COPD, using pulmonary function test (PFT) and CPET.

\section{MATERIALS AND METHODS Study participants}

The relevant population consisted of consecutive, clinically stable patients with a diagnosis of severe COPD (GOLD stage III) ${ }^{14}$ who visited the Respiratory Unit of Shanghai Pulmonary Hospital as outpatients between December 2011 and November 2013. Patients were diagnosed as clinically stable if they had had no hospital admission, exacerbation, respiratory infection or change in medication 3 months prior to entering the study. Exclusion criteria included: (1) a history of bronchiectasis, asthma or other concomitant respiratory diseases; (2) a diagnosis of malignancy; (3) inability to complete CPET according to the American Thoracic Society/ American College of Chest Physicians guidelines, ${ }^{15}$ such as unstable angina, acute myocardial infarction, uncontrolled arrhythmias causing symptoms and orthopaedic impairment and (4) any disease that could affect haemoglobin $(\mathrm{Hb})$ levels (thyroid disease, liver disease, chronic renal failure, chronic heart failure, history of gastrointestinal bleeding and chronic inflammatory rheumatic disease). Anaemia was defined as the presence of $\mathrm{Hb}$ levels $<12 \mathrm{~g} / \mathrm{dL}$ in males and $<11 \mathrm{~g} / \mathrm{dL}$ in females according to China-specific criteria. ${ }^{16}$

\section{Study procedures}

During the initial visit, all the patients with a potential or known diagnosis of COPD underwent physical examination, arterial blood gas (ABG) analysis and lung function testing. All patients with stable severe COPD (if $30 \% \leq$ forced expiratory volume $\left(\mathrm{FEV}_{1}\right) \leq 50 \%$ predicted) underwent peripheral venous blood sampling to determine full blood count, liver transaminase, total protein (albumin and globulin), thyroid hormone, serum levels of urea and creatinine. Patients who subsequently presented with abnormal thyroid hormone values (either high or low), glomerular filtration rate below $60 \mathrm{~mL} / \mathrm{min}^{17}$ and increased liver enzymes twice the upper limit of normal were excluded. The patients included in the study visited the outpatient clinic within 2 weeks from the initial visit and performed CPET.

\section{$A B G$ analysis and resting pulmonary function measurements}

ABG measurements such as $\mathrm{pH}$, partial pressure of oxygen $\left(\mathrm{PaO}_{2}\right)$, partial pressure of carbon dioxide $\left(\mathrm{PaCO}_{2}\right)$ and arterial oxygen saturation $\left(\mathrm{SaO}_{2}\right)$ were taken just after $10 \mathrm{~min}$ of rest. Each participant underwent resting PFT of forced vital capacity (FVC), $\mathrm{FEV}_{1}$, inspiratory capacity (IC), diffusing capacity for carbon monoxide (DLCO) corrected by $\mathrm{Hb}$, residual volume (RV) and total lung capacity (TLC) using standard methodology 12 and equipment (Jaeger Corp, Hoechberg, Germany). All resting lung function values were reported in absolute terms and normalised to percentage of predicted (\% pred). Predicted spirometry values were calculated using accepted equations for Chinese adults. ${ }^{19}$

\section{CPET measurements}

All the patients performed on a cycle ergometer using a breath-by-breath system according to the American Thoracic Society/American College of Chest Physicians Statement on CPET. ${ }^{15}$ The equipment was calibrated in accordance with the manufacturer's specifications using reference and calibration gases before each test. Standard 12 lead ECGs and pulse oximetry were continuously monitored. Arterial blood pressure was measured every 2 min with an automatic cuff. The protocol comprised $3 \mathrm{~min}$ of rest and $3 \mathrm{~min}$ of unloaded cycling at $55-65 \mathrm{rpm}$, followed by a progressively increasing work rate of $5-15 \mathrm{~W} / \mathrm{min}$ for the patients with COPD and 4 min of recovery. ${ }^{19}$

Most CPET values were reported in absolute terms and normalised to \%pred. Predicted values were calculated using accepted equations. ${ }^{19}$ CPET variables including oxygen uptake $\left(\dot{\mathrm{VO}}_{2}\right)$, minute ventilation $(\dot{\mathrm{V}})$, carbon dioxide output $\left(\mathrm{VCO}_{2}\right)$, work rate $(\mathrm{WR})$ and dead space/tidal volume ratio (VD/VT) were calculated at peak exercise. PeakV $\mathrm{V}_{2}$ was defined as the highest $30 \mathrm{~s}$ average of oxygen uptake in the last minute of exercise and other peak parameters were calculated at the same time. Lowest $\dot{\mathrm{VE}} / \mathrm{VCO}_{2}$ was determined by averaging the lowest consecutive $90 \mathrm{~s}$ data points. ${ }^{20}$

\section{Statistical analysis}

Statistical analysis was performed using SPSS (V.16, SPSS, Chicago). Parameters were expressed as mean \pm SD. Most PFT and CPET values are expressed in absolute terms and \%pred. Unpaired Student t test was used to identify differences between groups, whereas $\chi^{2}$ test was used to assess differences in categorical variables between groups. Correlations between CPET parameters and $\mathrm{Hb}$ levels were determined by Pearson's correlation test. A $p$ value of $<0.05$ was considered significant.

\section{RESULTS}

\section{Baseline clinical and demographic characteristics}

One hundred and fifty-seven patients diagnosed with severe COPD (GOLD stage III) in outpatients were included. The vast majority $(93 \%)$ of patients in the data set were males. The mean age was 61 years. The characteristics of the patients with COPD with anaemia and without anemia are presented in table 1 . Forty-eight $(31 \%)$ patients from this population fulfilled laboratory 
Table 1 Demographic and clinical characteristics of patients included in the study

\begin{tabular}{|c|c|c|}
\hline Variable & $\begin{array}{l}\text { Patients with low haemoglobin } \\
\text { concentration (\%) }\end{array}$ & $\begin{array}{l}\text { Patients with normal haemoglobin } \\
\text { concentration (\%) }\end{array}$ \\
\hline Number of patients $(n=157)(\%)$ & $48(31 \%)$ & $109(69 \%)$ \\
\hline Sex & Men (M) 45(94\%) & Men (M) 99 (91\%) \\
\hline Age (years) & $61.32 \pm 6.03$ & $60.82 \pm 7.13$ \\
\hline BMI $\left(\mathrm{kg} / \mathrm{m}^{2}\right)$ & $21.72 \pm 2.93$ & $22.18 \pm 2.15$ \\
\hline Haemoglobin concentration ( $\mathrm{g} / \mathrm{dL})$ & $10.6 \pm 0.8^{\star}$ & $12.9 \pm 1.1^{*}$ \\
\hline $\operatorname{MCV}(f L)$ & $85.9 \pm 9.1$ & $87.1 \pm 10.2$ \\
\hline Smoking index (pack-years) & $43.58 \pm 7.70$ & $45.56 \pm 4.63$ \\
\hline $\mathrm{pH}$ & $7.39 \pm 0.017$ & $7.38 \pm 0.023$ \\
\hline $\mathrm{PaCO}_{2}(\mathrm{~mm} \mathrm{Hg})$ & $44.67 \pm 1.32$ & $44.31 \pm 1.28$ \\
\hline $\mathrm{PaO}_{2}(\mathrm{~mm} \mathrm{Hg})$ & $68.11 \pm 3.01$ & $67.33 . \pm 3.62$ \\
\hline $\mathrm{SaO}_{2}(\%)$ & $94.44 \pm 0.94$ & $94.77 \pm 1.13$ \\
\hline
\end{tabular}

criteria for anaemia, and therefore the prevalence of anaemia among outpatients with stable COPD (GOLD stage III) in our study was $31 \%$. The $\mathrm{Hb}$ level for patients with anaemia was $10.6 \pm 0.8 \mathrm{~g} / \mathrm{dL}$. No difference was noted in body mass index, ages, pack-years of smoking and $\mathrm{ABG}$ analysis parameters $\left(\mathrm{pH}, \mathrm{PaO}_{2}\right.$, $\mathrm{PaCO}_{2}$ or $\mathrm{SaO}_{2}$ ) between patients with anemia and without anemia.

\section{Resting pulmonary function measurements}

The PFT parameters of the patients with anemia and without anemia are presented in table 2. There was no statistical significance in $\mathrm{FEV}_{1}, \mathrm{FEV}_{1} \%$ pred, $\mathrm{FEV}_{1} / \mathrm{FVC}$, IC, RV, TLC, RV/TLC between the two groups, indicating that resting pulmonary ventilation function was similar in both patient groups. However, DLCO

Table 2 Comparison of pulmonary function indices in patients with COPD with and without anaemia

\begin{tabular}{|c|c|c|}
\hline Variable & $\begin{array}{l}\text { Patients with low } \\
\text { haemoglobin } \\
\text { concentration } \\
(n=48)\end{array}$ & $\begin{array}{l}\text { Patients with normal } \\
\text { haemoglobin } \\
\text { concentration } \\
(n=109)\end{array}$ \\
\hline $\mathrm{FEV}_{1}(\mathrm{~L})$ & $1.33 \pm 0.27$ & $1.41 \pm 0.13$ \\
\hline FEV $_{1}$ (\%pred) & $42.15 \pm 7.53$ & $43.28 \pm 5.72$ \\
\hline $\mathrm{FEV}_{1} / \mathrm{FVC}(\%)$ & $41.32 \pm 2.19$ & $43.36 \pm 1.38$ \\
\hline $\mathrm{RV}(\mathrm{L})$ & $3.98 \pm 1.55$ & $4.11 \pm 1.24$ \\
\hline TLC (L) & $7.82 \pm 0.93$ & $7.11 \pm 1.78$ \\
\hline RV/TLC (\%) & $50.12 \pm 6.78$ & $53.27 \pm 6.79$ \\
\hline IC (L) & $1.52 \pm 0.47$ & $1.61 \pm 0.43$ \\
\hline DLco (L) & $15.31 \pm 1.94^{*}$ & $17.10 \pm 2.05^{\star}$ \\
\hline \multicolumn{3}{|c|}{ 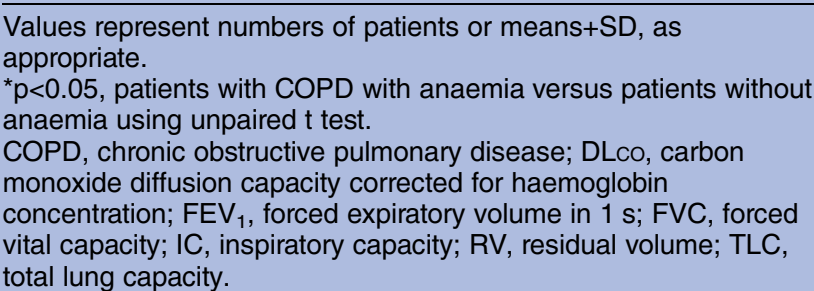 } \\
\hline
\end{tabular}

corrected by $\mathrm{Hb}$ was significantly lower among patients with anaemia compared with patients without anaemia.

\section{Cardiopulmonary exercise testing}

All individuals completed their CPET studies without incident. Nearly all patients stopped exercise because of leg fatigue and/or acute shortness of breath. All participants achieved a respiratory exchange ratio (RER) $>1.10$, indicating sufficient metabolic stress. Since the anaerobic threshold (AT) may not be determined by the V-slope method ${ }^{21}$ or the interpreter may feel that AT is

Table 3 Comparison of cardiopulmonary exercise testing parameters in patients with COPD with and without anaemia

\begin{tabular}{|c|c|c|}
\hline Variable & $\begin{array}{l}\text { Patients with } \\
\text { low } \\
\text { haemoglobin } \\
\text { concentration }\end{array}$ & $\begin{array}{l}\text { Patients with } \\
\text { normal } \\
\text { haemoglobin } \\
\text { concentration }\end{array}$ \\
\hline Peak Load (W) & $66.36 \pm 16.62^{*}$ & $69.46 \pm 28.18^{*}$ \\
\hline Peak $\dot{\mathrm{V}} \mathrm{O}_{2}(\mathrm{~mL} / \mathrm{min})$ & $866.28 \pm 274.32^{\star \star}$ & $1180.42 \pm 319.18^{\star \star}$ \\
\hline Peak $\dot{\mathrm{VO}} 2$ (\%pred) & $56.21 \pm 14.79^{\star *}$ & $69.11 \pm 18.72^{\star \star}$ \\
\hline $\begin{array}{l}\text { Peak } \dot{\mathrm{V}} \mathrm{O}_{2} / \mathrm{kg} \\
(\mathrm{mL} / \mathrm{min} / \mathrm{kg})\end{array}$ & $14.88 \pm 3.92^{*}$ & $18.72 \pm 3.86^{*}$ \\
\hline Peak VंE (L/min) & $37.89 \pm 6.33$ & $36.71 \pm 5.42$ \\
\hline $\begin{array}{l}\Delta \mathrm{O}_{2} / \Delta \mathrm{WR} \text { slope } \\
(\mathrm{mL} / \mathrm{min} / \mathrm{W})\end{array}$ & $8.02 \pm 1.03^{*}$ & $9.20 \pm 1.42^{*}$ \\
\hline $\begin{array}{l}\text { Peak } \mathrm{O}_{2} \text { pulse } \\
\text { (mL/beat) }\end{array}$ & $7.88 \pm 2.63^{\star}$ & $11.3 \pm 2.19^{\star}$ \\
\hline Lowest $\dot{\mathrm{VE}} / \mathrm{V} \mathrm{CO}_{2}$ & $32.15 \pm 1.28$ & $31.28 \pm 2.90$ \\
\hline Peak VD/VT (\%) & $33.2 \pm 7.2$ & $34.9 \pm 6.1$ \\
\hline
\end{tabular}

Values represent numbers of patients or means+SD, as appropriate.

${ }^{*} p<0.05,{ }^{* *} p<0.01$, patients with COPD with anaemia versus patients without anaemia using unpaired Student $t$ test. $\Delta \mathrm{O}_{2} / \Delta$ WR slope, the ratio of $\mathrm{VO}_{2}$ increase to WR increase; $\%$ pred, percentage of predicted; COPD, chronic obstructive pulmonary disease; $\dot{\mathrm{V}} \mathrm{CO}_{2}$, carbon dioxide output; $\dot{\mathrm{V} E}$, minute ventilation; $\mathrm{VO}_{2}$, Peak oxygen uptake; VD/VT, dead space/tidal volume ratio. 
unreliable after reviewing an exercise test in a substantial number of patients with severe COPD, CPET variables including $\dot{\mathrm{V}} \mathrm{O}_{2}, \dot{\mathrm{VE}}, \dot{\mathrm{V}} \mathrm{CO}_{2}$, workload and VD/VT were calculated at peak exercise without AT. Exercise responses of all the patients with COPD at peak are presented in table 3. Overall, there was a negative impact of anaemia on exercise capacity. Peak Load, Peak $\dot{\mathrm{V}} \mathrm{O}_{2}$, Peak $\dot{\mathrm{V}} \mathrm{O}_{2} / \mathrm{kg}$, Peak $\dot{\mathrm{V}} \mathrm{O}_{2}$ pulse and the ratio of $\dot{\mathrm{V}} \mathrm{O}_{2}$ increase to $\mathrm{WR}$ increase $\left(\Delta \dot{\mathrm{V}} \mathrm{O}_{2} / \Delta \mathrm{WR}\right.$ slope $)$ were significantly lower among patients with anaemia compared with patients without anaemia. None of the exercise parameters indicative of respiratory limitation and ventilatory efficiency (Peak $\dot{\mathrm{VE}}$, Lowest $\dot{\mathrm{VE}} / \dot{\mathrm{V}} \mathrm{CO}_{2}$, Peak VD/ VT) differed between the two groups.

\section{Correlations}

Peak $\dot{\mathrm{V}} \mathrm{O}_{2}$ is frequently used as the most reliable measure of overall exercise capacity, so we choose Peak $\dot{\mathrm{V}}_{2}$ as the typical CPET parameters to investigate for potential associations between $\mathrm{Hb}$ levels and exercise capacity. The correlations between $\mathrm{Hb}$ concentration and Peak $\mathrm{V}_{2}$ for the patients with COPD with anemia and without anemia are shown in figure 1. A strong positive correlation was found between $\mathrm{Hb}$ concentration and Peak $\dot{\mathrm{V}} \mathrm{O}_{2}$ in patients with anaemia $(\mathrm{r}=0.702$, $\mathrm{p}<0.01$ ) (figure $1 \mathrm{~A}$ ), but no statistical significant correlation was found with patients without anaemia $(\mathrm{r}=0.055$, $\mathrm{p}>0.05$ ) (figure $1 \mathrm{~B}$ ).

\section{DISCUSSIONS}

In this study, anaemia was present in $31 \%$ of patients with severe COPD. The prevalence of anaemia was higher than in patients from previous studies, ${ }^{3-12}$ possibly because the study population comprised patients with more severe COPD. The result confirms that anaemia is a common phenomenon in patients with severe COPD. The main aim of this study was to search for potential correlations between patients with anaemia with severe COPD and resting pulmonary function and
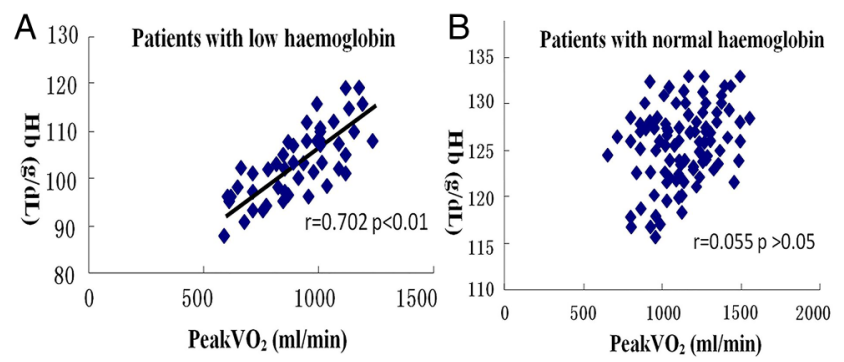

Figure 1 ( $A$ and $B$ ) Showing the correlation between Peak $\dot{\mathrm{V}} \mathrm{O}_{2}$ and haemoglobin $(\mathrm{Hb})$ concentration in patients with COPD with and without anaemia, respectively. Significant positive correlation was found between $\mathrm{Hb}$ concentration and Peak $\dot{\mathrm{VO}}_{2}$ in patients with anaemia $(r=0.702, p<0.01)(A)$, but no statistical significant correlation was found with patients without anaemia $(r=0.055, p>0.05)(B)$. exercise capacity, as well as ventilatory efficiency based on PFT and CPET.

The usual PFT parameters like $\mathrm{FEV}_{1}, \mathrm{FEV}_{1} \%$ pred, $\mathrm{FEV}_{1} / \mathrm{FVC}, \mathrm{IC}, \mathrm{RV}$, TLC and RV/TLC of the two groups were similar to each other except for DLCO corrected by $\mathrm{Hb}$. A severe obstructive pattern characterised the population studied. The finding that patients in the anaemia group had significantly lower DLCO values (corrected by $\mathrm{Hb})(\mathrm{p}<0.05)$ indicates that the decreased level of $\mathrm{Hb}$ may affect the rate of oxygen uptake across the alveolocapillary bed and reduce the diffusing capacity of the lungs, without having an obvious influence on the pulmonary ventilation function. Studies examining the effect of just anaemia or anaemia combined with disorder of the alveolocapillary membrane consistently mention that anaemia does affect the diffusion capacity, but the defect of the respiratory membrane on diffusing capacity is greater. ${ }^{22}{ }^{23}$ In this study, we have patients with COPD and anaemia who commonly also have defect with the respiratory membrane, both contributing to the reduced DLco as noted. We think that the initial poor correlation with blood gases in this study is because the compensatory mechanisms are not yet fully dysfunctional and the anaemia not severe. Also, all patients in the study were clinically stable and under adequate medication.

Although anaemia has been associated with dyspnoea and reduced exercise tolerance in patients with chronic kidney disease, heart failure and cancer, ${ }^{24-26}$ few studies have been published concerning the effect of anaemia on exercise capacity in patients with COPD. Cote $e t a l^{27}$ studied patients with stable COPD, observed that the presence of anaemia affects the general feeling of dyspnoea measured in the Medical Research Council (MRC) scale and concluded that anaemia decreases exercise tolerance measured in 6 min walk test (6MWT). However, this study is the first to investigate the impact of anaemia on the exercise capacity and ventilatory efficiency of patients with severe COPD using CPET in the Chinese population.

On the one hand, this study showed that patients with anaemia with severe COPD had lower Peak Load, Peak $\dot{\mathrm{V}} \mathrm{O}_{2}$ (\%pred), Peak $\dot{\mathrm{V}} \mathrm{O}_{2} / \mathrm{kg}, \Delta \mathrm{O}_{2} / \Delta \mathrm{WR}$ slope and Peak oxygen pulse $\left(\mathrm{O}_{2}\right.$ pulse $)$ compared with those without anaemia, demonstrating the negative effect of anaemia on exercise capacity. Peak $\mathrm{V}_{2}$ is frequently used as the most reliable measure of overall exercise capacity. By Fick's principle, ${ }^{20}{ }^{28-30} \quad \dot{\mathrm{VO}_{2}=\text { cardiac output } \times \text { arteriove- }}$ nous $\mathrm{O}_{2}$ difference, the arteriovenous $\mathrm{O}_{2}$ difference is dependent on the availability of $\mathrm{Hb}$, blood oxygenation in the lung, and extraction of oxygen in the periphery. For a given increase in cardiac output, the patient with anaemia, who has a decreased level of $\mathrm{Hb}$ and arterial $\mathrm{O}_{2}$ concentration, will have a lower Peak $\dot{\mathrm{V}} \mathrm{O}_{2}$. The $\mathrm{O}_{2}$ pulse is the quotient of the $\dot{\mathrm{V}}_{2}$ and heart rate. The $\Delta \dot{\mathrm{V}} \mathrm{O}_{2} / \Delta \mathrm{WR}$ slope is an important measurement to evaluate exercise capacity in patients with heart disease. The decreased $\Delta \mathrm{VO}_{2} / \Delta \mathrm{WR}$ slope is a marker of 
decreased aerobic exercise capacity caused by decreased oxygen transport. ${ }^{31}$ In our study, we found that patients with COPD with anaemia had a lower $\Delta \mathrm{VO}_{2} / \Delta \mathrm{WR}$ slope than those without anaemia. This result confirms that patients with anaemia may have a more serious limitation in exercise capacity than patients without anemia, corroborating with the study by Boutou et $a l^{32}$ Further still, unlike those including other groups as well, we just included participants with GOLD stage III. This study also differs in the fact that we have a larger sample size and the anaemia cut-off values were pertinent to the Chinese population rather than the WHO defined general cut-off values for anaemia. Unlike in our study, Rutten $e t a l^{33}$ reported that the $6 \mathrm{~min}$ walk distance (6MWD) and the BODE (Body mass index, airflow Obstruction, Dyspnoea, and Exercise capacity) score were not different among the patients with and without anaemia. However, the patient profiles in our study are fundamentally different from those of Rutten $e t a l$ as we have taken a lower $\mathrm{Hb}$ cut-off value to define anaemia. Nevertheless, the patients in our study have much lower $\mathrm{Hb}$ levels on average, indicating that the degree of anaemia was more severe. On the other hand, there were no differences in CPET parameters as Peak $\dot{\mathrm{V} E}$, Lowest $\dot{\mathrm{VE}} / \dot{\mathrm{V}} \mathrm{CO}_{2}$ and Peak VD/VT (\%) between the two groups. Both Peak VD/VT and Lowest $\dot{\mathrm{VE}} / \mathrm{V}_{\mathrm{V}} \mathrm{CO}_{2}$ indicate the ventilatory efficiency of oxygen uptake and carbon dioxide elimination in patients, mainly due to the limitation of blood flow perfusion, that is, perfusion/ventilation (Q/VA) mismatch. Therefore, anaemia may have a negative effect on the exercise capacity of patients with severe COPD, while its influence on ventilatory efficiency is little.

Apart from that, a strong positive correlation was found between $\mathrm{Hb}$ concentration and Peak $\mathrm{V}_{2}$ in patients with anaemia $(r=0.702, p<0.01)$, but no statistically significant correlation was found with patients without anaemia. All these results strongly indicate that the oxygen carrying capacity may depend on the level of $\mathrm{Hb}$ of the patients with anaemia and oxygen delivery is crucial for the maintenance of oxidative metabolism. A previous study showed that in normal individuals, $15 \mathrm{~g} / \mathrm{dL}$ of $\mathrm{Hb}$ carries approximately $21 \mathrm{~mL}$ of oxygen per $100 \mathrm{~mL}$ of blood and a $3 \mathrm{~g} / \mathrm{dL}$ decrease in $\mathrm{Hb}$ levels would result in a reduction of the total oxygencarrying capacity by $4 / 100 \mathrm{~mL}{ }^{34}$ Moreover, anaemia may result in limited oxygen supply with the consequent increase in ventilatory drive. Among patients with COPD whose ventilatory reserves were decreased, the accompanying increased ventilatory demand may result in dyspnoea.

Our study is not free of limitations. The proportion of female patients was small. The significantly lower prevalence of COPD in females is a possible explanation for this phenomenon. Moreover, the present data were derived from patients with severe COPD (GOLD stage III) and thus cannot be applied to the overall population of patients with COPD. The reason why we chose patients with severe COPD (GOLD stage III) as our object of study is that patients with anaemia had a tendency to have more severe COPD, ${ }^{32} 35$ while patients with very severe COPD may not manage to complete CPET. Efforts should be made to further assess the prevalence of anaemia in other stages of COPD.

\section{Conclusions}

Our study demonstrated that COPD can be accompanied by anaemia and implied the potential correlations between anaemia in patients with COPD and respiratory physiology using PFT and CPET. The results indicated that both the function of gas exchange and exercise capacity decreased in the patients with severe COPD with anaemia compared with the patients without anaemia, while the influence of anaemia on pulmonary ventilation function and ventilatory efficiency was little. Future studies are needed in order to evaluate the possible therapeutic approaches in patients with COPD with anaemia.

\section{Author affiliations}

${ }^{1}$ Department of Pulmonary Function Test, Shanghai Pulmonary Hospital, Tongji University School of Medicine, Shanghai, China

${ }^{2}$ Department of Respiratory Diseases, Shanghai Changning District Central Hospital, Shanghai, China

${ }^{3}$ Department of Pulmonary Circulation, Shanghai Pulmonary Hospital, Tongji University School of Medicine, Shanghai, China

${ }^{4}$ State Key Laboratory of Cardiovascular Disease, Heart-Lung Function Testing Center, Fuwai Hospital, National Center for Cardiovascular Diseases, Chinese Academy of Medical Sciences and Peking Union Medical College, Beijing, China

Contributors $\mathrm{JL}, \mathrm{XSu}, \mathrm{JG}$ and $\mathrm{CZ}$ conceived and designed the experiments. JG, CZ, QX and WY performed the experiments. JL, JG, CZ, QX, SG and QZ analysed the data. $\mathrm{JH}$ contributed to tools, in this case the exercise machine; LW contributed to materials; JG, JL and XSh contributed to the analysis. JL, $J G, C Z$ and $Q X$ wrote the manuscript.

Funding This research received no specific grant from any funding agency in the public, commercial or not-for-profit sectors.

Competing interests None declared.

Patient consent Obtained.

Ethics approval The study was approved by the hospital Ethics Committee.

Provenance and peer review Not commissioned; externally peer reviewed.

Data sharing statement No additional data are available.

Open Access This is an Open Access article distributed in accordance with the Creative Commons Attribution Non Commercial (CC BY-NC 4.0) license, which permits others to distribute, remix, adapt, build upon this work noncommercially, and license their derivative works on different terms, provided the original work is properly cited and the use is non-commercial. See: http:// creativecommons.org/licenses/by-nc/4.0/

\section{REFERENCES}

1. Antonelli-Incalzi R, Fuso L, De Rosa M, et al. Co-morbidity contributes to predict mortality of patients with chronic obstructive pulmonary disease. Eur Respir J 1997;10:2794-800.

2. Zielinski J. Effects of long-term oxygen therapy in patients with chronic obstructive pulmonary disease. Curr Opin Pulm Med 1999;5:81-7.

3. John M, Hoernig S, Doehner W, et al. Anemia and inflammation in COPD. Chest 2005;127:825-9. 
4. Chambellan A, Chailleux E, Similowski T, ANTADIR Observatory Group. Prognostic value of hematocrit in patients with severe COPD receiving long-term oxygen therapy. Chest 2005;128:1201-8.

5. John M, Lange A, Hoernig S, et al. Prevalence of anemia in chronic obstructive pulmonary disease: comparison to other chronic diseases. Int J Cardiol 2006;111:365-70.

6. Martinez FJ, Foster G, Curtis JL, et al., NETT Research Group. Predictors of mortality in patients with emphysema and severe airflow obstruction. Am J Resp Crit Care Med 2006;173:1326-34.

7. Shorr AF, Doyle J, Stern L, et al. Anemia in chronic pulmonary disease: epidemiology and economic implications. Curr Med Res Opin 2008;24:1123-30.

8. Barnes PJ, Celli BR. Systemic manifestations and comorbidities of COPD. Eur Resp J 2009;33:1165-85.

9. Cosio MG, Saetta M, Agusti A. Immunologic aspects of chronic obstructive pulmonary disease. N Engl J Med 2009;360:2445-54.

10. Kollert $F$, Müller $C$, Tippelt $A$, et al. Anaemia in chronic respiratory failure. Int J Clin Pract 2011;65:479-86.

11. Kollert F, Tippelt A, Müller C, et al. Hemoglobin levels above anemia thresholds are maximally predictive for long-term survival in COPD with chronic respiratory failure. Respir Care 2013;58:1204-12.

12. Boutou AK, Karrar S, Hopkinson NS, et al. Anemia and survival in chronic obstructive pulmonary disease: a dichotomous rather than a continuous predictor. Respiration 2013;85:126-31.

13. Ferrazza AM, Martolini D, Valli G, et al. Cardiopulmonary exercise testing in the functional and prognostic evaluation of patients with pulmonary diseases. Respiration 2009;77:3-17.

14. Spirometry for Health Care Providers: Quick Guide. Global Initiative for Chronic Obstructive Lung Disease (GOLD). http://www.goldcopd. org (accessed 1 Feb 2013).

15. American Thoracic Society; American College of Chest Physicians. ATS/ACCP Statement on cardiopulmonary exercise testing. Am J Respir Crit Care Med 2003;167:211-77.

16. Wenbin C, Youchi W, Hongda W. Diagnostics. 5th edn. Peking: People's Health Publishing House, 2002.

17. Hsu CY, McCulloch CE, Curhan GC. Epidemiology of anaemia associated with chronic renal insufficiency among adults in the United States: results from the Triad National Health and Nutrition Examination Survey. J Am Soc Nephrol 2002;13:504-10.

18. Mu K, Liu S. Summary of Chinese pulmonary function normal values. Beijing Medical University and Peking Union Medical College Press, 1990;2:83-6.

19. Wasserman K, Hansen JE, Sue DY, et al. Principles of exercise testing and interpretation. 5th edn. Philadelphia: Lippincott, Williams \& Wilkins, 2011:568

20. Sun XG, Hansen JE, Garatachea N, et al. Ventilatory efficiency during exercise in healthy subjects. Am J Respir Crit Care Med 2002;166:1443-8.
21. Beaver WL, Wasserman K, WHIPP BJ, et al. A new method for detecting anaerobic threshold by gas exchange. J Appl Physiol 1986;60:2020-7.

22. Maras-Simunić M, Tocilj J, Simunić M. The effect of hemoglobin levels in the blood in pulmonary diffusing capacity. Lijec Vjesn 1994;116:22-5.

23. Petermann W. Effect of low hemoglobin levels on the diffusing capacity of the lungs for $\mathrm{CO}$. Investigations in persons with healthy lungs and in patients with interstitial pulmonary fibrosis. Respiration 1985;47:30-8.

24. Lim VS, DeGowin RL, Zavala D, et al. Recombinant human erythropoietin treatment in pre-dialysis patients. A double-blind placebo-controlled trial. Ann Intern Med 1989;110:108-14.

25. Dudgeon DJ, Lertzman M, Askew GR. Physiological changes and clinical correlations of dyspnea in cancer outpatients. J Pain Symptom Manage 2001;21:373-9.

26. Mancini DM, Katz SD, Lang CC, et al. Effect of erythropoietin on exercise capacity in patients with moderate to severe chronic heart failure. Circulation 2003;107:294-9.

27. Cote $\mathrm{C}$, Zilberberg MD, Mody SH, et al. Haemoglobin level and its clinical impact in a cohort of patients with COPD. Eur Respir $J$ 2007;29:923-9.

28. Wasserman K. Cardiopulmonary exercise testing and cardiovascular health. Armonk, NY: Future, 2002.

29. Sun $X G$, Hansen JE, Ting $H$, et al. Comparison of exercise cardiac output by the Fick principle using oxygen and carbon dioxide. Chest 2000;118:631-40

30. Stringer WW, Hansen JE, Wasserman K. Cardiac output estimated noninvasively from oxygen uptake during exercise. J Appl Physiol 1997;82:908-12.

31. Corrà U, Piepoli MF, Task Force of the Italian Working Group on Cardiac Rehabilitation and Prevention. Official document on cardiopulmonary exercise testing in chronic heart failure due to left ventricular dysfunction recommendations for performance and interpretation. Monaldi Arch Chest Dis 2007;68:6-12.

32. Boutou AK, Stanopoulos I, Pitsiou GG, et al. Anemia of chronic disease in chronic obstructive pulmonary disease: a case-control study of cardiopulmonary exercise responses. Respiration 2011;82:237-45.

33. Rutten EP, Franssen FM, Spruit MA, et al. Anemia is associated with bone mineral density in chronic obstructive pulmonary disease. COPD 2013;10:286-92.

34. Culver BH. Physiology. In: Albert RK, Spiro SG, Jett JR, eds. Comprehensive respiratory medicine. 1st edn. St Louis, Mosby Inc 1999:89-150.

35. Watz H, Waschki B, Boehme C, et al. Extrapulmonary effects of chronic obstructive pulmonary disease on physical activity. Am J Respir Crit Care Med 2008;177:743-51. 